\title{
Family functioning integrated with diabetes self-management: a concept analysis
}

Rian Adi Pamungkas ${ }^{a, b, c, * *}$, Kanittha Chamroonsawasdia, Paranee Vatanasomboon ${ }^{d}$

${ }^{a}$ Department of Family Health, Mahidol University, Bangkok 10400, Thailand

${ }^{b}$ Department of Nursing, College of Health, Bina Generasi, Polewali 91315, Indonesia

'Department of Nursing, College of Health, Marendeng Majene 91411, Indonesia

${ }^{d}$ Department of Health Education and Behavioral Science, Mahidol University, Bangkok 10400, Thailand

Received: 20 December 2017; accepted: 28 April 2018; Published: 20 September 2018

Abstract: Although the concept of family functioning has gained recent popularity, the terms "family functioning" and "family resilience" are sometimes confused and used interchangeably. The aim of this concept analysis was to clarify what is meant by family functioning in the context of diabetes self-management by assessing specific attributes, antecedents, and consequences. A concept analysis model by Walker and Avant was applied. The identified attributes of family functioning in a diabetes self-management context included problem-solving, communication, roles, affective responsiveness, affective involvement, and behavioral control. Antecedents included family structure, socioeconomic status, family functioning relationships, family stage, and life events. Consequences included family satisfaction, family cohesion, and family relationships. This analysis provided a deeper understanding of a family functioning concept within a diabetes self-management context. It is recommended that health care providers should be aware of antecedent factors that could inhibit outcome improvement. Further research is needed to explain family functioning attributes in relation to antecedents and potential consequences.

Keywords: family functioning $\bullet$ concept analysis $•$ diabetes $\bullet$ self-management

\section{Introduction}

Diabetes mellitus (DM) is a significant public health problem worldwide. The World Health Organization (WHO) predicts that 422 million people are currently living with DM. ${ }^{1}$ Several complications are associated with DM, including diabetic retinopathy, nephropathy, neuropathy, cardiovascular disease, amputations, and premature death. ${ }^{2}$

Diabetes self-management is relatively complex given that individuals have to attend medical appointments regularly, adhere to several different medications, control their symptoms through physical activity, blood glucose monitoring, and foot care, and negotiate barriers to management and psychosocial problems. ${ }^{3}$

* Corresponding author.

E-mail: adirian491@yahoo.com (R. -A. Pamungkas).

O Open Access. ๑ 2018 Rian Adi Pamungkas et al., published by Sciendo. Attribution NonCommercial-NoDerivatives 4.0 License.
Family members are a potentially useful support system for diabetes self-management. Much diabetes management takes place within a close social environment. ${ }^{4}$ Therefore, addressing family functioning within diabetes self-management is important, as disease management is mostly facilitated within a family context. However, family functioning contexts are currently unclear and difficult to differentiate from family resilience when a chronic illness is present. ${ }^{5}$

The terms "family functioning" and "family resilience" are sometimes confused and used interchangeably; this is because both terms are related to a family's adaptation and dynamic processes when confronted with stress emanating from a chronic illness. A better understanding of family functioning could clarify ways to help the family and patient maintain balance and functioning when providing diabetes care. 
Conceptualizing family functioning with regard to diabetes care provides an essential foundation for developing effective and sensitive interventions that promote growth among individual family members and the family unit as a whole.

Concept analyses provide precise operational definitions, refine ambiguous concepts within a theory, and provide a more basic and deeper understanding of underlying attributes within a concept. Eight steps, first identified by Walker and Avant, are conducted: (a) select a concept, (b) determine the purpose of the analysis, (c) identify all uses of the concept, (d) determine the defining attributes, (e) construct a model case, (f) identify antecedents, (g) identify consequences, and (h) define empirical referents. ${ }^{6}$

\section{Methods}

This initial review included articles that shared relevance with a standard literature review. For initial strategies, "family functioning," "self-management," and "type 2 diabetes" (T2DM) were the main search terms, and these terms needed to be observed either in the abstract or in the title of the study.

\subsection{Eligibility criteria}

To describe family functioning within diabetes selfmanagement among T2DM patients, the researchers used the following article inclusion criteria. Specifically, descriptive articles of how a family integrated with diabetes self-management were included. Design types included descriptive studies, qualitative studies, and intervention studies that focused on diabetes prevention and diabetes self-management.

\subsection{Search strategy}

The researcher used PubMed, Scopus, and Google Scholar to find the relevant articles related to family functioning integrated with diabetes self-management for T2DM patients. The search strategy used in this review included "family functioning," "self-management," and "type 2 diabetes."

\subsection{Synthesis of results}

Results of this review are explained narratively. The descriptions of results include the following: (1) definition of family functioning; (2) defining attributes of family functioning integrated with diabetes self-management; (3) model case on applying family functioning integrated with diabetes self-management, antecedents, consequences, and empirical referents.

\section{Defining family functioning}

Family functioning is defined as the process by which the family system completes a series of tasks, including basic tasks (e.g., managing individual needs such as food and clothing living line, and money management), developmental tasks (e.g., adapting and promoting the growth and development of members), and crisis tasks (e.g., dealing with all kinds of family emergencies). ${ }^{7}$

\section{Defining attributes}

Attributes are defined as characteristics that appear repeatedly with reference to the concept. These defining attributes assist the researcher in differentiating similar concept definitions. ${ }^{6}$ Defined attributes were as follows: (a) problem-solving, (b) communication, (c) roles, (d) affective responsiveness, (d) affective involvement, and (e) behavioral control (Table 1).

\begin{tabular}{|c|c|}
\hline $\begin{array}{l}\text { Family functioning } \\
\text { attributes }\end{array}$ & Items/components/skills \\
\hline Problem-solving & $\begin{array}{l}\text { Problem identification and agreement; creating } \\
\text { options and alternatives surrounding the } \\
\text { identified problem; ensuring quality of the family } \\
\text { emotional problem; taking proper measures } \\
\text { to solve problems; monitoring progress and } \\
\text { successful plan of action }\end{array}$ \\
\hline Communication & $\begin{array}{l}\text { Instrumental communication such as the } \\
\text { exchange of factual information that enables } \\
\text { individuals to fulfill common family functions; } \\
\text { affective communication is a means by which } \\
\text { individual family members share their emotions } \\
\text { with one another }\end{array}$ \\
\hline Family roles & $\begin{array}{l}\text { Instrumental roles concerned with the provision } \\
\text { of physical resources (providing food, clothing, } \\
\text { and shelter) and affective roles, including } \\
\text { the ability to provide emotional support } \\
\text { and encouragement to family members; } \\
\text { development of life skills (physical, emotional, } \\
\text { educational, and social development of all } \\
\text { children and adults) }\end{array}$ \\
\hline $\begin{array}{l}\text { Affective } \\
\text { responsiveness }\end{array}$ & $\begin{array}{l}\text { The ability to respond to a situation with } \\
\text { appropriate emotions. This includes affection, } \\
\text { warmth, tenderness, love, consolation, and } \\
\text { happiness }\end{array}$ \\
\hline $\begin{array}{l}\text { Affective } \\
\text { involvement }\end{array}$ & $\begin{array}{l}\text { Emotional distance between family members; } \\
\text { family members respect each other's } \\
\text { personality, interest, hobbies, and satisfaction }\end{array}$ \\
\hline Behavioral control & $\begin{array}{l}\text { Determining the family's style of behavioral } \\
\text { control; suggestions for developing a healthy } \\
\text { family behavioral style }\end{array}$ \\
\hline
\end{tabular}

Table 1. Family functioning items, components, and skills.

\subsection{Problem-solving}

Problem-solving can be defined as the family's capacity to solve problems to maintain effective family 
functioning. This is similar to notions of finding a solution to avoid threatening the integrity and functioning of the family's capacity. ${ }^{8}$ The family members who successfully resolve problems are capable of dealing with both instrumental and emotional issues. In a diabetes context, problem-solving skills are required to manage behavioral issues, including how to manage a healthy diet, increase physical activity, and monitor blood glucose and psychological problems (e.g., feelings of denial, negative responses to diabetes selfmanagement, and depression). ${ }^{9-11}$ Problem-solving also requires addressing whether an intervention is of sufficient potency and intensity in terms of treatment dose and duration for effective self-management. ${ }^{12}$ Family members emphasize effective feedback concerning negative perceptions to reduce care resistance and build a patient's self-efficacy. ${ }^{13}$

\subsection{Communication}

Communication is defined as the process by which information is exchanged within a family. Family members need to communicate and coordinate to address thought and feeling patterns that emerge during diabetes care. ${ }^{14}$ Within the communication concept, emotional expressions could promote the role of family members in helping the patient with problem-solving and supporting self-management. ${ }^{15}$

With regard to diabetes care, open and supportive communication among patients and family members is important. ${ }^{16}$ For instance, patients often express a willingness to educate family members regarding increased T2DM risk and primary prevention. ${ }^{17}$ Communication also influences emotional support and the ability to obtain valuable information and increase family cohesion. ${ }^{18}$ This is performed to manage diabetes behaviors, promote effective day-to-day coping, reduce care resistance, and enhance self-efficacy. ${ }^{13}$ One study suggested that augmenting communication skills during diabetes management helps with problem-solving and behavior change to achieve goals relevant to tailored interventions. Overall, this can improve communication skills during discussion tasks, goal setting, and problem-solving. ${ }^{19}$

\subsection{Roles}

Roles are patterns underlying a family's behavior which are established by family members to complete effective functioning. ${ }^{20}$ To achieve the certain social and family expectations in DMSM practice, patients themselves and their family members should fulfil those roles. In this article, the family role is subdivided into instrumental and affective types. Instrumental roles include money management or deciding on diabetes treatment. Affective roles focus on the feelings and emotional experiences related to implementing diabetes self-management. Family member roles include facilitating, accommodating, reminding, and motivating patients to complete self-management tasks, help with decision-making and problem-solving, connect to outside resources, provide emotional support, and facilitate patient-provider communication. ${ }^{21}$

\subsection{Affective responsiveness}

Affective responsiveness can be defined as family members' ability to respond to outside stimuli with appropriate feelings. This could facilitate various aspects related to task accomplishment and successful role integration. ${ }^{15}$

Being able to positively respond to other family members with a wide range of emotions is key to successful family functioning. Specific family members are some of the best sources of support for diabetes self-management. To respond with appropriate emotions, several affective responsiveness skills are needed, and they include the following: staying tuned to what is going on in the lives of other family members, being empathic within a given situation, appropriately control and express anger, and verbally express love and appreciation for other family members as well as joy in other members' accomplishments. ${ }^{14}$

\subsection{Affective involvement}

Affective involvement is the degree of concern and attention that family members give to activities among each other. This could help or hinder task accomplishment within the family ${ }^{20}$ and influence the ability of a family member to meet emotional barriers and security needs as well as the flexibility to provide support. ${ }^{15}$

One study conducted with elderly patients whose spouses were involved with care observed positive effects regarding adherence to diabetes management, higher self-esteem, enhanced ability to address barriers, and the development of supportive relationships among family members as compared with those patients lacking such support. ${ }^{22}$

However, some conflicts often occur within the family since lifestyle changes are required for optimal diabetes self-management. ${ }^{23}$ Family members also can disrupt or undercut self-care efforts (e.g., planning healthy meals or question medication adherence). ${ }^{24}$ Therefore, diabetes self-management should focus on the family as an intervention target to better equip the family with the ability to provide support and care. ${ }^{25}$ 


\subsection{Behavioral control}

Behavioral control is key to successful family functioning; it is often defined as the pattern a family adopts for handling specific behaviors. ${ }^{20}$ In this process, the family members should be capable of maintaining ongoing functioning as well as should adapt to shifting task demands. Family behaviors are important for patients with T2DM which require consistent and active selfmanagement. This often involves changes to daily routines, including changes in eating patterns, physical activity, and regular self-testing for blood glucose, cholesterol, blood pressure, etc. ${ }^{26}$ Family system theory emphasizes positive family functioning influencing individual functioning by facilitating interconnectedness for managing diabetes. ${ }^{27}$

One study reported that families who are able to adapt to specific situations are better able to solve problems. Thus, a flexible behavioral control style could improve a family's ability to overcome challenges through a family contract system. ${ }^{14}$ Hence, families can identify interests and concerns that may need to be changed, including family-style behaviors.

\section{Model case}

Walker and Avant described a model case that demonstrates "all defining attributes of the concept." The example case is provided as follows:

A 60-year-old man with a 6-year history of type 2 diabetes mellitus. Although he was diagnosed in 2011, he had symptoms 3 years before diagnosis. The $\mathrm{HbA} 1 \mathrm{c}$ records indicated values of $8 \%$, which was categorized as poor glycemic control. He had poor eating habits and was not exercising. He really loved to eat large pastas and sweet foods. At the time of initial diagnosis, he was advised to lose weight, but no further action was taken. Referred by his family physician, he was required to decrease his weight and control his blood glucose. He has been trying to lose weight and increase his exercise for the past 6 months without success. He started with glyburide, $2.5 \mathrm{mg}$, every morning but had stopped taking it because of dizziness, often accompanied by sweating and a feeling of mild agitation. He stopped these supplements when he did not see any positive results. He does not test his blood glucose levels at home and expresses doubt that this procedure would help him improve his diabetes control. The patient was required to do multiple tasks for self-management, including attending a regular medical appointment each month, adhere to medication regimens, and engage in self-care behaviors (i.e., at-home blood glucose monitoring, control his diet, and increase physical activity). However, it is often difficult for him to consistently engage in these health behaviors that are necessary for good glycemic control. Common barriers include competing daily demands, frustration, other emotional distress, low self-commitment, lack of knowledge, low levels of self-efficacy to successfully complete an activity, and insufficient social support from family members. To change and maintain positive selfmanagement behaviors, family members were tasked with helping the patient with strategic planning and goal setting. Effective feedback concerning negative diabetes perceptions and good communication was also used for exchanging health information, reducing care resistance, and building self-efficacy emphasized by family members. Additionally, during diabetes treatment, family members emphasized cultural beliefs and values to help support dietary change, physical activity, and blood glucose monitoring. This was done in order to help the patient feel appreciated. Regarding emotional supportive behaviors, family members assessed psychosocial problems. A patient can express negative responses to diabetes self-management, a seasonal mood disorder, and/or the presence of depression due to the illness or retirement during treatment. However, family members are on his side in order to provide emotional support, as well as help with problem-solving. This strategy can boost adherence to medication regimens, encourage a healthy diet, and maintain exercise behaviors. The patient-family relationship, cohesion, and patient-family member communication were achieved.

This model case illustrates successful achievement of all family functioning attributes for effective diabetes self-management. This model also provides information regarding family functioning and means for supporting patients with specific self-management tasks, such as healthy eating habits, selecting appropriate physical activity, blood glucose monitoring, foot care, and stress management. Effective feedback and exchanging health information reflect good communication, emphasizing cultural beliefs and values for generating supportive behaviors as part of family functioning. This includes affective involvement, emotional support, and instrumental support for diabetes care. Outcomes include effective responses from family members, and problemsolving was emphasized when the patient showed negative responses to self-management, depression, and retirement during long-term treatment. From this model case, it is understood that effectiveness of family functioning could influence relationship roles, family cohesion, and family communication for managing patients' behavior.

\section{Antecedents}

Walker and Avant defined antecedents as events that must occur prior to the emerging concept. The factors 
considered as antecedents for implementing family functioning for supporting care include family structure, socioeconomic status, family functioning relationships, family stage, and life events that could impact outcomes. ${ }^{7}$ Managing these factors could influence basic family functioning to provide appropriate environmental conditions for members to complete a series of tasks, including basic tasks (e.g., managing the material needs of the individual such as food and clothing living line), developmental tasks (e.g., adapting and promoting the growth and development of each member), and crisis tasks (e.g., dealing with all kinds of family emergencies). ${ }^{8}$

The review also revealed relationships between the highest levels of family functioning styles with family values and resource mobilization for patients with T2DM. ${ }^{28}$ Other factors influencing family functioning include parental age, socioeconomic level, ${ }^{29}$ educational attainment, and sibling relationships. ${ }^{30}$ In addition, higher income was positively correlated with better physical and mental health, greater longevity, fewer stressful life events, and greater successes. ${ }^{29,31}$

\section{Consequences}

Walker and Avant defined consequences as events that occur as a result of the emerging concept. Consequences of family functioning have been demonstrated by research related to diabetes management. Family functioning significantly influences a sense of satisfaction and family cohesion. ${ }^{32}$ In addition, family functioning is positively affected by diabetes management, illustrating the protective nature of a positive family environment in relation to achieving the most favorable health outcomes. ${ }^{33}$ At this point, family functioning may be very helpful in moving the family toward a better level of diabetic control. It is generally accepted that a lack of family functioning leads to declines in diabetic control and can even negatively affect a child's functioning in areas such as personality, physical well-being, and activity participation. ${ }^{34}$

\section{Empirical referents}

Empirical referents are defined as classes or categories of actual phenomena that, by their existence or presence, demonstrate the emergence of a concept. Some instruments are identified for measuring family functioning within the area of chronic disease, including the Family Assessment Device (FAD) survey, ${ }^{8}$ Family Functioning Index (FFI), ${ }^{37}$ Family Adaptability, Partnership, Growth, Affection, and Resolve Index (AFGAR), ${ }^{38}$ Family Assessment Measure (FAM), ${ }^{15}$ and the Chinese version of the Survey of Family Environment (SFE). ${ }^{39}$
Epstein et al. ${ }^{8}$ used a 60 -item instrument that listed family functioning to identify families experiencing problems, highlighting specific domains and assessing change following treatment. This instrument had seven categories, including problem-solving, communication, role function, affective responsiveness, affective involvement, behavioral control, and overall functioning. The FAD is composed of four statement responses ${ }^{1-4}$ for each subscale, and the individual scale scores range from 1.0 (best functioning) to 4.0 (worst functioning). This instrument is considered with high internal consistency (Cronbach's $\alpha=0.74-0.92$ ).

Satterwhite et al. ${ }^{37}$ created the FFI to reflect dynamics within family interactions, an important intervening variable in terms of social and medical outcomes when providing care for a chronic physical disorder. The FFI appears to be a reliable and valid instrument with testretest correlation scores between 0.74 and 0.83 . A total of 15 self-reported dyadic and whole family questions (yes/no on a 5-point rating scale) are grouped into five functions: marital satisfaction, frequency of divergence, communication, problem-solving, happiness, and intimacy. ${ }^{37}$ The scores range from 0.07 to 0.96 for fathers and 2.1 to 0.95 for mothers.

AFGAR is used to assess a family member's perception of family functioning by examining patient's satisfaction with family relationships. The measure consists of five family functioning parameters: adaptability, partnership, growth, affection, and resolve. The scale is measured on a 5-point scale ranging from 0 "never" to 4 "always." The largest possible score is 20 ; a score of $\square 9$ is considered dysfunctional; $10-12$ is moderate family dysfunction; 13-16 points are mild family dysfunction; and $17-20$ points are good functionality. The AFGAR is a reliable instrument with good internal consistency (Cronbach's $\alpha=0.80-0.85$ ) and item-to-total correlations ranging from 0.50 to 0.65 . Initial validity was also established with a correlation of 0.80 (the latter $=0.64$ ). ${ }^{38}$

Skinner et al. ${ }^{15}$ developed the FAM based on the process model of family functioning. This model described seven key dimensions: task accomplishment, role performance, communication, affective expression, involvement, control, and values and norms. Fourteen items are scored on a 4-point Likert scale ranging from "strongly agree" to "strongly disagree." The FAM is measured at three levels, including the whole family system (general scale, 50 items), various dyadic relationships (dyadic scale, 42 items), and individual functioning (self-rated scale, 42 items). The FAM appears to be a reliable and valid instrument with coefficient alphas ranging from 0.60 to 0.80 . The overall FAM ratings yield substantial alpha coefficients: adults $=0.93$ general scale, 0.95 dyadic relationships, 0.89 self-rating; children $=0.94$ general scale, 0.94 dyadic relationships, and 0.86 self-rating (Table 2 ). 


\begin{tabular}{ll}
\hline Study & Dimension of family functioning \\
\hline \hline Olson et al. ${ }^{35}$ & - Family intimacy (relationships between family members) \\
& - Family adaptability (the family needs to change the power structure, role assignment, or ability of family roles \\
& to cope with external environmental pressures) \\
& - Family communication (communication between family members) \\
& - Rigid index (family structure, family relationship, and family reaction force \\
Beavers and Hampson ${ }^{36}$ & - Soft index (family members' communication style) \\
& - Problem-solving (ability to solve problems) \\
Miller et al. ${ }^{20}$ & - Communication (ability to share information between family members) \\
& - Family role (ability of family members to establish behavior patterns) \\
& - Affective response (degree of emotional responses to a problem) \\
& - Affective involvement (degree of concern regarding activities related to behaviors) \\
& - Behavioral control (ability to control behavior in different family situations) \\
& - Task completion \\
Skinner et al. ${ }^{15}$ & - Role \\
& - Communication \\
& - Emotional expression \\
& - Family involvement \\
& - Family behaviors, values, and roles
\end{tabular}

Table 2. Dimensions of family functioning.

The SFE consists of 30 items that examine family functioning and family support needs which consist of 5 structures including supra-system, macro-system, micro-system, family internal environment system, and chrono-system. All items are scored on a 5-point Likert scale ( 1 = "dissatisfied/unimportant," 5 = "satisfied/ important") with scores ranging from 1 to 25 points.
Internal consistency is high (0.92). In a test-retest study of 33 families, the correlation coefficient was 0.93 , indicating the high test-retest reliability. The instrument consists of three dimensions: relationships between family members, relationship between the family and subsystem, and relationship between the family and society. ${ }^{39}$ (Table 3 )

\begin{tabular}{|c|c|c|c|}
\hline Instrument & Study & Item dimensions & Instrument characteristics \\
\hline FAD survey & Miller et al. ${ }^{20}$ & $\begin{array}{l}\text { - Problem-solving } \\
\text { - Communication } \\
\text { - Role function } \\
\text { - Affective response } \\
\text { - Involvement } \\
\text { - Behavioral control } \\
\text { - Overall functioning }\end{array}$ & $\begin{array}{l}\text { 5-point Likert scale: (1) strongly disagree, } \\
\text { (2) disagree, (3) agree, (4) strongly agree }\end{array}$ \\
\hline $\mathrm{FFI}$ & Satterwhite et al. ${ }^{37}$ & $\begin{array}{l}\text { - Marital satisfaction } \\
\text { - Frequency of divergence } \\
\text { - Communication } \\
\text { - Problem-solving } \\
\text { - Happiness and intimacy }\end{array}$ & $\begin{array}{l}15 \text { self-report dyadic and whole family } \\
\text { questions (yes/no and 5-point rating } \\
\text { scale) }\end{array}$ \\
\hline AFGAR & Smilkstein et al. ${ }^{38}$ & $\begin{array}{l}\text { - Adaptation } \\
\text { - Cooperation } \\
\text { - Growth } \\
\text { - Emotion } \\
\text { - Problem-solving }\end{array}$ & $\begin{array}{l}\text { 10-point scale: highly dysfunctional } \\
(0-3), \text { moderately dysfunctional }(4-6) \text {, } \\
\text { and highly functional }(7-10)\end{array}$ \\
\hline FAM & Skinner et al. ${ }^{15}$ & $\begin{array}{l}\text { - Task accomplishment } \\
\text { - Role performance } \\
\text { - Communication } \\
\text { - Affective expression } \\
\text { - Involvement } \\
\text { - Control } \\
\text { - Values } \\
\text { - Norms }\end{array}$ & $\begin{array}{l}3 \text { levels: (1) general scale ( } 50 \text { items, nine } \\
\text { subscales, (2) dyadic relationship scale } \\
\text { ( } 42 \text { items, seven subscales), ( } 3 \text { ) self- } \\
\text { rating scale ( } 42 \text { items, seven subscales) }\end{array}$ \\
\hline $\begin{array}{l}\text { The Chinese version } \\
\text { of the FFFS } \\
\text { (Chinese FFFS) }\end{array}$ & Honda et al. ${ }^{39}$ & $\begin{array}{l}\text { - Relationship between family members } \\
\text { - Relationship between the family and subsystem } \\
\text { - Relationship between the family and society }\end{array}$ & $\begin{array}{l}\text { 5-point Likert scale: (1) dissatisfied } \\
\text { (2) somewhat dissatisfied, (3) neither } \\
\text { satisfied nor dissatisfied, (4) somewhat } \\
\text { satisfied, (5) satisfied }\end{array}$ \\
\hline
\end{tabular}

Table 3. Instrument measures for family functioning. 
AFGAR, Family Concern Index Questionnaire; FAD, Family Assessment Device; FAM, Family Assessment Measure; FFI, Family Functioning Index; FFFS, Feetham Family Functioning Survey.

The differences between the five instruments are the dimensions measured and settings to which each scale is applied. However, different attributes have been identified in this concept analysis, and unique aspects of the reviewed concept lead to some divergence. Thus, specific instruments could be modified based on the specific family functioning definitions.

\section{Conclusions}

The main findings suggest a clarification of defining attributes, antecedents, consequences, and empirical referents related to family functioning in diabetes selfmanagement. The concept of family functioning is made up of several dimensions, including problem-solving, communication, family roles, affective responsiveness, affective involvement, and behavioral control. These attributes are associated with factors known to serve as antecedents, including family structure, socioeconomic status, family functioning relationship, family stage, and life events. The goal of better understanding of family functioning is to ultimately improve health outcomes, family satisfaction, family cohesion, and family relationships. Thus, fully elucidating the concept of family functioning

\section{References}

1. American Diabetes Association. Foundations of care: education, nutrition, physical activity, smoking cessation, psychosocial care, and immunization. Diabetes Care. 2015;38(suppl):S20-S30.

2. American Diabetes Association. Classification and diagnosis of diabetes. Diabetes Care. 2017;40(suppl 1):S11-S24.

3. American Diabetes Association. Standards of medical care in diabetes-2014. Diabetes Care. 2014;37(suppl 1):S14-S80.

4. World Health Organization. Innovative Care for Chronic Conditions: Building Blocks for Action: Global Report. Geneva: World Health Organization; 2002.

5. Lee I, Lee E-O, Kim HS, Park YS, Song M, Park $\mathrm{YH}$. Concept development of family resilience: a study of Korean families with a chronically ill child. J Clin Nurs. 2013;13:636-645.

6. Walker LO, Avant KC. Strategies for Theory Construction in Nursing. 4th ed. New Jersey: Pearson Prentice Hall. 2005. in diabetes self-management could improve health outcomes and provide provisions for health care providers to more appropriately engage services among diabetes patients and their family members. Hence, this review recommends that health care providers become aware of, and consider, the antecedents underlying family functioning concepts for promoting positive health outcomes.

\section{Acknowledgments}

The authors would like to thank Mahidol University for facilitating the database search necessary for this review. The authors would like to give special thanks also to the Indonesia Endowment Fund for Education (Lembaga Pengelolah Dana Pendidikan [LPDP] scholarship) and Ministry of Higher Education and Research for grant support.

\section{Compliance with ethical standard}

The Endowment Fund for Education provided a grant funding for this review (S-3937/LPDP.3/2016). The funding sponsors also had no role in the writing of the manuscript or any decision to publish this manuscript.

\section{Conflicts of interest}

All contributing authors declare no conflicts of interest.

7. Dai L, Wang L. Review of family functioning. Open $J$ Soc Sci. 2015;3:134-141.

8. Epstein N, Baldwin L, Bishop D. The McMaster family assessment device. J Fam Ther. 1983;9:171-180.

9. Hu J, Wallace DC, McCoy TP, Amirehsani KA. A family-based diabetes intervention for Hispanic adults and their family members. Diabetes Educ. 2014;40:48-59

10. Garcia-Huidobro D, Bittner M, Brahm P, Puschel K. Family intervention to control type 2 diabetes: a controlled clinical trial. Fam Pract. 2011;28:4-11.

11. Vincent D. Culturally tailored education to promote lifestyle change in Mexican Americans with type 2 diabetes. J Am Acad Nurse Pract. 2009;21:520-527.

12. Fitzpatrick SL, Schumann KP, Hill-Briggs F. Problem solving interventions for diabetes self-management and control: a systematic review of the literature. Diabetes Res Clin Pract. 2013;100:145-161.

13. Keogh KM, Smith SM, White P, et al. Psychological family intervention for poorly controlled type 2 diabetes. Am J Manage Care. 2011;17:105-113. 
14. Peterson R, Green S. Families First: Keys to Successful Family Functioning Communication. Virginia: Virginia State University; 2009. http://pubs. ext.vt.edu/350/350-092/350-092.html

15. Skinner H, Steinhauer P, Sitarenios G. Family assessment measure and process model of family functioning. J Fam Ther. 2000;22:190-210.

16. Wiseman M, Dancyger C, Michie S. Communicating genetic risk information within families: a review. Fam Cancer. 2010;9:691-703.

17. van Esch SC, Cornel MC, Geelhoed-Duijvestijn PH, Snoek FJ. Family communication as strategy in diabetes prevention: an observational study in families with Dutch and Surinamese South-Asian ancestry. Patient Educ Couns. 2012;87:23-29.

18. Williams IC, Utz SW, Hinton I, Yan G, Jones R, Reid K. Enhancing diabetes self-care among rural African Americans with diabetes: results of a twoyear culturally tailored intervention. Diabetes Educ. 2014;40:231-239.

19. Trief P, Sandber JG, Ploutz-Snyder R, et al. Promoting couples collaboration in type 2 diabetes: the diabetes support project pilot data. Fam Syst Health. 2011;29:253-261.

20. Miller IW, Ryan CE, Keitner GI, Bishop DS, Epstein NB. The McMaster Approach to Families: theory, assessment, treatment and research. J Fam Ther. 2000;22:168-189.

21. Rosland A-M. Sharing the care: the role of family in chronic illness. Calif Health Care Found. 2009;1-27.

22. Baig AA, Benitez A, Quinn MT, Burnet DL. Family interventions to improve diabetes outcomes for adults. Ann N Y Acad Sci. 2015;1353:89-112.

23. Denham SA, Manoogian MM, Schuster L. Managing family support and dietary routines: type 2 diabetes in rural Appalachian families. Fam Syst Health. 2007;25:36-52.

24. Carter-Edwards L, Skelly AH, Cagle CS, Appel S. "They care but don't understand": family support of African American women with type 2 diabetes. Diabetes Educ. 2004;30:493-501.

25. Mayberry LS, Osborn CY. Family support, medication adherence, and glycemic control among adults with type 2 diabetes. Diabetes Care. 2012;35:1239-1245.

26. Rosland AM, Heisler M, Piette JD. The impact of family behaviors and communication patterns on chronic illness outcomes: a systematic review. J Behav Med. 2012;35:221-239.
27. Lutz BJ, Chumbler NR, Lyles T, Hoffman N, Kobb R. Testing a home-telehealth programme for US veterans recovering from stroke and their family caregivers. Disabil Rehabil. 2009;31:402-409.

28. Boylu AA, Copur Z, Oztop $H$. Investigation of the factors influencing family functions style. Int $J$ Res Bus Soc Sci. 2016;2:2147-4478.

29. Keklikoglou I, Koerner C, Schmidt C, et al. MicroRNA-520/373 family functions as a tumor suppressor in estrogen receptor negative breast cancer by targeting NF-kappaB and TGF-beta signaling pathways. Oncogene. 2012;31:4150-4163.

30. Nalavany BA, Ryan SD, Hinterlong J. Externalizing behavior among adopted boys with preadoptive histories of child sexual abuse. J Child Sex Abuse. 2009;18:553-573.

31. Leung JTY, Shek DTL. Parental beliefs and family functioning in Chinese families experiencing economic disadvantage in Hong Kong. Int J Disabil Hum Dev. 2013;12:151-161.

32. Whitehead AL, Dimmock M, Place M. Diabetes control and the influence of family functioning. J Diabetes Res Clin Metab. 2013;2:1-16.

33. Mackey ER, Hilliard ME, Berger SS, Streisand R, Chen R, Holmes $C$. Individual and family strengths: an examination of the relation to disease management and metabolic control in youth with type 1 diabetes. Fam Syst Health. 2011;29:314-326.

34. Donnelly LA, Morris AD, Evans JM; DARTS/MEMO Collaboration. Adherence to insulin and its association with glycaemic control in patients with type 2 diabetes. QJM. 2007;100:345-350.

35. Olson DH, Sprenkie DH, Russell CS. Circumplex model of marital and family systems: I. Cohesion and adaptability dimension, family types and applications. Fam Process. 1979;18:3-28.

36. Beavers R, Hampson RB. The Beavers systems model of family functioning. J Fam Ther. 2000;22:128-143.

37. Satterwhite BB, Zweig SR, Iker HP, Pless B. The family functioning index - five year test-retest reliability and implications for use. J Comp Fam Stud. 1997;7:111-116.

38. Smilkstein G, Ashworth C, Montano D. Validity and reliability of the family APGAR as a test of family function. J Fam Pract. 1982;15:303-311.

39. Honda J, Hohashi N, Kam Leung S. Reliability and validity of the Chinese Version of the Survey of Family Environment (SFE). Open J Nurs. 2016;6:820-832.

How to cite this article: Pamungkas RA, Chamroonsawasdi K, Vatanasomboon P. Family functioning integrated with diabetes self-management: a concept analysis. Front Nurs. 2018; 3: 199-206. https://doi.org/10.1515/ fon-2018-0027. 